\title{
Muscle Layer
}

National Cancer Institute

\section{Source}

National Cancer Institute. Muscle Layer. NCI Thesaurus. Code C75444.

The smooth muscle component of an organ, especially of a hollow org an or tubular structure. 